Jakub Rybar - Lubica Stuchlikova - Ladislav Harmatha - Juraj Jakus - Jaroslav Kovac Beata Sciana - Damian Radziewicz - Damian Pucicki - Wojciech Dawidowski - Marek Tlaczala *

\title{
DLTS STUDY OF InGaAsN/GaAs p-i-n DIODE
}

The paper presents an in-depth DLTS characterization of the p-i-n structure based on the InGaAsN/GaAs triple quantum well. Three DLTS evaluation methods were used for evaluation of the measured DLTS spectra. The results of all evaluation methods are compared and discussed. One of the evaluation methods that were used is a novel numerical algorithm that was recently developed. Several material and growth defects were identified. Emission from the quantum well was also observed and identified. The parameters of the energy levels were calculated and compared. The studied InGaAsN/GaAs structure is promising candidate for the solar cell applications and the further refinement of the growth process and technology is encouraged.

Keywords: DLTS, deep energy level, InGaAsN, p-i-n, multijunction solar cells.

\section{Introduction}

One of the very promising materials in optoelectronics is a new class of semiconductors known as dilute nitrides. These dilute nitrides with nitrogen concentrations less than $5 \%$, are opening the door for several key technologies in the near-infrared, particularly for optical fiber communication and solar cells applications. Dilute nitrides such as GaInNAs can be grown directly on gallium arsenide, which allows wellestablished processing techniques [1]. Unusual properties of the $\mathrm{In}_{\mathrm{y}} \mathrm{Ga}_{1-\mathrm{y}} \mathrm{As}_{1-\mathrm{x}} \mathrm{N}_{\mathrm{x}}$ semiconductor alloys such as a huge and negative band gap bowing coefficient and a large conduction band offset make this semiconductor very promising for applications in high efficient multijunction solar cells [2].

DLTS (Deep Level Transient Spectroscopy) study of the p-i-n structure based on the triple quantum well InGaAsN/GaAs heterostructure is introduced in the paper. The structure was grown by atmospheric pressure metalorganic vapor phase epitaxy.
In order to determine the origin of the traps detected in this sample, we had to use several evaluation methods of measured DLTS spectra and compare the evaluated results of all used methods. The measured data were compared with other similar structures [3] and thus it was possible to determine, whether the deep energy levels are caused by emission from quantum well or by presence of material defects in the structure. This paper summarizes the results of the in-depth study of this very interesting p-i-n structure with QW (quantum well), which is promising candidate for the solar cell applications.

\section{Experiment}

The p-i-n diode labeled NI71n based on InGaAsN/GaAs multi-quantum well structure was investigated in this experiment (Table 1 and Fig. 1 list the parameters of the sample). The investigated sample was manufactured at Wroclaw University

The parameters of the p-i-n diode structure labeled NI71n

\begin{tabular}{|c|c|c|c|c|c|c|c|c|c|c|}
\hline \multirow[t]{2}{*}{ Sample } & \multirow[t]{2}{*}{ Substrate } & \multirow[t]{2}{*}{ Buffer } & \multirow[t]{2}{*}{ Buffer } & \multicolumn{3}{|c|}{$\begin{array}{c}\text { 3xUD In } \mathrm{Ga}_{\mathrm{y}-\mathrm{y}} \mathrm{As}_{1-\mathrm{x}} \mathrm{N}_{\mathrm{x}} \\
\text { quantum wells }\end{array}$} & \multirow{2}{*}{$\begin{array}{l}\text { UD GaAs } \\
\text { barrier }\end{array}$} & \multirow{2}{*}{$\begin{array}{l}\text { UD } \\
\text { GaAs }\end{array}$} & \multirow{2}{*}{$\begin{array}{c}\text { p-GaAs: } \\
\text { Zn }\end{array}$} & \multirow{2}{*}{$\begin{array}{c}\mathrm{p}^{+}-\mathrm{GaAs}: \\
\mathrm{Zn}\end{array}$} \\
\hline & & & & thickness (nm) & $\mathrm{y}(\%)$ & $\mathrm{x}(\%)$ & & & & \\
\hline \multirow{2}{*}{ NI71n } & \multirow{2}{*}{$\begin{array}{l}\text { n-GaAs:Si } \\
\quad(100)\end{array}$} & $\mathrm{n}^{+}-\mathrm{GaAs}: \mathrm{Si}$ & UD-GaAs & $8.8 \mathrm{~nm}$ & 8.0 & 0.47 & \multirow{2}{*}{$22.5 \mathrm{~nm}$} & \multirow{2}{*}{$0.45 \mu \mathrm{m}$} & 0.25 & „сар“ \\
\hline & & $0.30 \mu \mathrm{m}$ & $0.45 \mu \mathrm{m}$ & $8.8 \mathrm{~nm}$ & 17.0 & 0.10 & & & $\mu \mathrm{m}$ & $50 \mathrm{~nm}$ \\
\hline
\end{tabular}

\footnotetext{
* 1'Jakub Rybar, 'Lubica Stuchlikova, ' Ladislav Harmatha, ' Juraj Jakus, ' Jaroslav Kovac,

${ }^{2}$ Beata Sciana, ${ }^{2}$ Damian Radziewicz, ${ }^{2}$ Damian Pucicki, ${ }^{2}$ Wojciech Dawidowski, ${ }^{2}$ Marek Tlaczala

${ }^{1}$ Institute of Electronics and Photonics, Faculty of Electrical Engineering and Information Technology,

Slovak University of Technology, Bratislava, Slovakia

E-mail: jakub.rybar@stuba.sk

${ }^{2}$ Wrocław University of Technology, Faculty of Microsystem Electronics and Photonics, Wroclaw, Poland
} 
of Technology using APMOVPE with AIX200 R\&D AIXTRON horizontal reactor on (100)-oriented Si-doped n-type GaAs substrate at specific growth conditions [4]. $3 \times \operatorname{In}_{y} \mathrm{Ga}_{1-y} \mathrm{As}_{1-x} \mathrm{~N}_{\mathrm{x}}$ quantum wells consist of two sub wells (Table 1). The top ohmic contact (area of $2 \times 10^{-2} \mathrm{~cm}^{2}$ ) was prepared by AuMn evaporation on $\mathrm{p}^{+} \mathrm{GaAs}: \mathrm{Zn}$ "cap" layer. The bottom ohmic contact was created by AuGeNi evaporation.

\begin{tabular}{|ll:l|}
\hline p- GaAs:Zn & "cap" & $50.0 \mathrm{~nm}$ \\
\hline $\mathrm{p}-\mathrm{GaAs}: \mathrm{Zn}$ & & $0.25 \mu \mathrm{m}$ \\
\hline UD GaAs & & $0.45 \mu \mathrm{m}$ \\
\hline UD InGaAsN & QW & $17.6 \mathrm{~nm}$ \\
\hline UD GaAs & barrier & $22.5 \mathrm{~nm}$ \\
\hline UD InGaAsN & QW & $17.6 \mathrm{~nm}$ \\
\hline UD GaAs & barrier & $22.5 \mathrm{~nm}$ \\
\hline UD InGaAsN & QW & $17.6 \mathrm{~nm}$ \\
\hline UD GaAs & buffer & $0.45 \mu \mathrm{m}$ \\
\hline $\mathrm{n}^{+}-\mathrm{GaAs}: \mathrm{Si}$ & buffer & $0.30 \mu \mathrm{m}$ \\
\hline $\mathrm{n}-\mathrm{GaAs:Si}(100)$ & substrate & \\
\hline
\end{tabular}

Fig. 1 Schematic description of the investigated structure

BIORAD DL8000 measurement system was used for measurement of the DLTS spectra in the temperature range from 80 to $550 \mathrm{~K}$. Apart from the standard DLTS maximum evaluation analysis, this measurement system is equipped with the Fourier transform analysis for the evaluation of the measured capacitance transients (Direct auto Arrhenius Single and Multilevel evaluation). An evaluation method that uses numerical algorithm and least square method for calculation of the deep energy level parameters (LSQ method) has been recently developed at our institute [5] and is suitable for evaluation of the studied structure. The obtained DLTS spectra were evaluated using all available DLTS evaluation methods.

\section{Results and discussion}

The evaluation of the measured DLTS spectra had resulted in the identification of several deep energy levels in the measured structure. Several sets of measurement conditions were used during the study of the sample. Fig. 2 depicts one of the measured DLTS spectra with the measurement conditions. The Arrhenius plot in Fig. 3 shows all the evaluated deep energy levels with their activation energies.

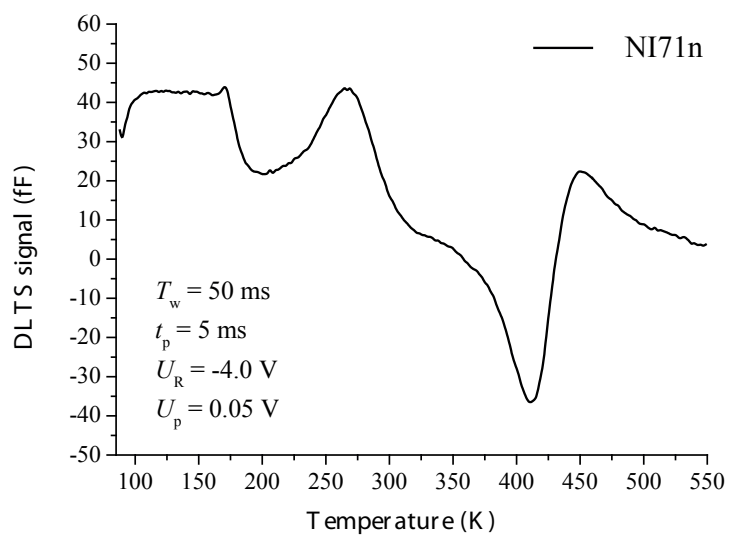

Fig. 2 Measured DLTS spectra with the measurement conditions

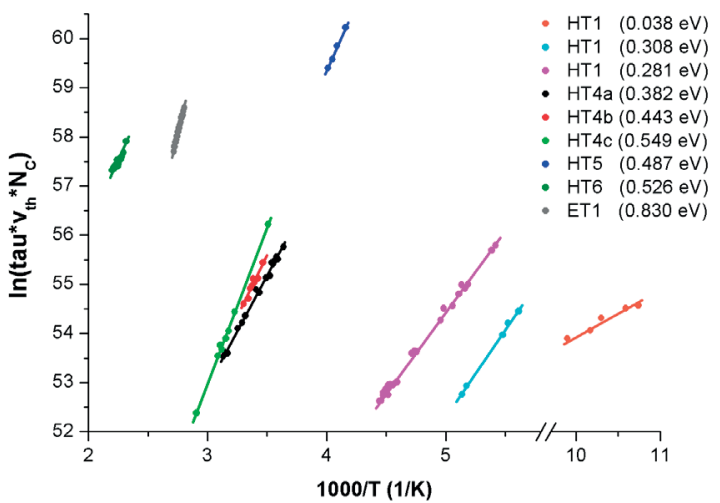

Fig. 3 Arrhenius plot of the evaluated and identified deep energy levels HTI-HT6 and ETI

Table 2 lists the evaluated deep energy levels with their parameters (activation energy $\Delta E_{\mathrm{T}}$, capture cross-section $\sigma_{\mathrm{T}}$, and trap concentration $N_{\mathrm{T}}$ ), the evaluation method type by which it was evaluated, and the probable origin of the deep energy level. The deep energy level HT1 (Table 2) was identified by evaluation with "min. class for evaluation" 40 and it's very interesting for a brief discussion. This hole-like level with rather small activation energy has a very small value of the capture cross-section. If we consider the fact that one of the most valuable properties of dilute nitride alloys is a discontinuity of the valence band equal to $150 \mathrm{meV}$ we may assume that the level HT1 $(0.038 \mathrm{eV})$ is related with this discontinuity and corresponds with the emission of the holes from the quantum well in the valence band. 


\begin{tabular}{|c|c|c|c|c|c|}
\hline $\begin{array}{l}\text { Energy } \\
\text { level }\end{array}$ & $\begin{array}{l}\text { Evaluation } \\
\text { method used }\end{array}$ & $\begin{array}{c}\text { Activation } \\
\text { energy } \\
\Delta E_{\mathrm{T}}(\mathrm{eV})\end{array}$ & $\begin{array}{c}\text { Capture } \\
\text { cross-section } \\
\text { prierez } \\
\sigma_{\mathrm{T}}\left(\mathrm{cm}^{2}\right)\end{array}$ & $\begin{array}{c}\text { Trap } \\
\text { concentration } \\
N_{\mathrm{T}}\left(\mathrm{cm}^{-3}\right)\end{array}$ & Probable origin \\
\hline \multirow{2}{*}{ HT1 } & MultiLevel & 0.038 & $1.1 \mathrm{E}-20$ & $3.4 \mathrm{E}+13$ & \multirow{2}{*}{ Emission from QW } \\
\hline & LSQ & 0.080 & $1.7 \mathrm{E}-20$ & $9.0 \mathrm{E}+13$ & \\
\hline \multirow{2}{*}{ HT2 } & MultiLevel & 0.308 & $1.2 \mathrm{E}-15$ & $6.5 \mathrm{E}+13$ & \multirow{2}{*}{ HL7 0.35 eV [6] } \\
\hline & LSQ & 0.309 & $6.0 \mathrm{E}-15$ & $6.2 \mathrm{E}+13$ & \\
\hline \multirow{2}{*}{ HT3 } & MultiLevel & 0.281 & $2.7 \mathrm{E}-17$ & $3.0 \mathrm{E}+13$ & \multirow{2}{*}{ HL12 0.27 eV [6] } \\
\hline & LSQ & 0.289 & $2.2 \mathrm{E}-16$ & $5.0 \mathrm{E}+13$ & \\
\hline HT4 & Single level & 0.200 & $4.7 \mathrm{E}-21$ & $1.1 \mathrm{E}+14$ & Summary signal \\
\hline \multirow{2}{*}{$\begin{array}{l}\text { HT4a } \\
\text { HT4b } \\
\text { HT4c }\end{array}$} & MultiLevel & $\begin{array}{l}0.382 \\
0.443 \\
0.549\end{array}$ & $\begin{array}{l}6.1 \mathrm{E}-18 \\
4.6 \mathrm{E}-17 \\
2.0 \mathrm{E}-15\end{array}$ & $\begin{array}{l}1.0 \mathrm{E}+14 \\
8.3 \mathrm{E}+13 \\
2.4 \mathrm{E}+14\end{array}$ & \multirow{2}{*}{$\begin{array}{c}\text { HL8 } 0.519 \mathrm{eV} \text { [6] } \\
\text { HM1 } 0.55 \mathrm{eV} \text { [7], }\end{array}$} \\
\hline & LSQ & $\begin{array}{l}0.385 \\
0.439 \\
0.549\end{array}$ & $\begin{array}{l}2.8 \mathrm{E}-17 \\
2.6 \mathrm{E}-17 \\
6.2 \mathrm{E}-15\end{array}$ & $\begin{array}{l}5.5 \mathrm{E}+13 \\
6.2 \mathrm{E}+13 \\
2.5 \mathrm{E}+13\end{array}$ & \\
\hline \multirow{2}{*}{ HT5 } & Single level & 0.487 & $1.1 \mathrm{E}-16$ & $8.2 \mathrm{E}+12$ & \multirow{2}{*}{ HL8 0.519 eV [6] } \\
\hline & LSQ & 0.480 & $1.0 \mathrm{E}-17$ & $1.9 \mathrm{E}+13$ & \\
\hline \multirow{2}{*}{ HT6 } & Single level & 0.526 & $1.0 \mathrm{E}-19$ & $4.7 \mathrm{E}+13$ & \multirow{2}{*}{$\mathrm{Fe} 0.54 \mathrm{eV}$ [9] } \\
\hline & LSQ & 0.529 & 8.0E-20 & $4.0 \mathrm{E}+13$ & \\
\hline \multirow{2}{*}{ ET1 } & Single level & 0.830 & $1.9 \mathrm{E}-14$ & $1.2 \mathrm{E}+13$ & \multirow{2}{*}{$\begin{array}{c}\text { EL2 } 0.831 \mathrm{eV} \\
{[10],[11]}\end{array}$} \\
\hline & LSQ & 0.815 & $9.5 \mathrm{E}-15$ & $7.4 \mathrm{E}+13$ & \\
\hline
\end{tabular}

Most of the energy levels that were evaluated were identified as well-known material defects of GaAs (HT2, HT3, HT4a, HT4b, HT4c, HT5, and ET1). Energy level HT2 was identified as HL7 with activation energy $\Delta E_{\mathrm{T}}=0.35 \mathrm{eV}$ [6], HT3 as HL12 with activation energy $\Delta E_{\mathrm{T}}=0.27 \mathrm{eV}$ [6]. Energy level HT3 is related to the contamination by zinc [6], which in case of the investigated sample is used as p-type doping in the upper GaAs layer. Energy level HT4 is in most measured DLTS spectra represented by single wide peak. In fact it consists of three peaks representing three energy levels HT4a, HT4b a HT4c. This information was obtained by Multi level Auto Arrhenius evaluation method. This evaluation method uses Fourier transformation and allows detailed analysis of the measured DLTS spectra, which can lead to identification of the component energy levels of the summary 
signal. The component energy levels HT4a, HT4b and HT4c were confirmed by the LSQ algorithm as well. Energy levels HT4a HT4b and HT4c were identified as defects related to the growth of GaAs (HL8 with activation energy $\Delta E_{\mathrm{T}}=0.519 \mathrm{eV}$ [6] and HM1 with activation energy $\Delta E_{\mathrm{T}}=0.55 \mathrm{eV}$, representing AsGa antisite [7] and [8]). Energy level HT5 corresponds with HL8 (activation energy $\Delta E_{\mathrm{T}}=0.519 \mathrm{eV}$ ) [6]. Energy level HT6 is related to iron contamination and has an activation energy $\Delta E_{\mathrm{T}}=0.54 \mathrm{eV}$ [9]. Energy level EL2 represents a well-known material defect of GaAs EL2 often found in bulk GaAs (activation energy of EL2: $\Delta E_{\mathrm{T}}=0.831 \mathrm{eV}$ [10], [11]). The results of the evaluation of the measured DLTS spectra by LSQ algorithm is depicted in Fig. 4.

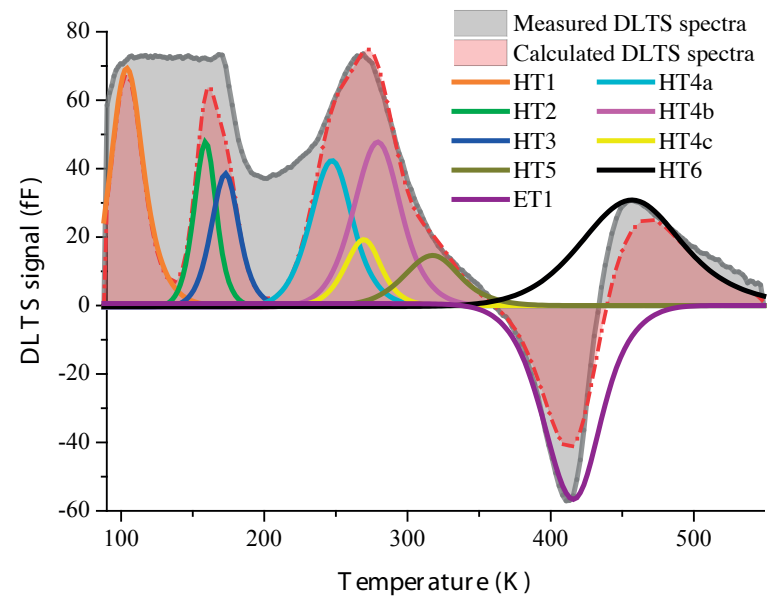

Fig. 4 Arrhenius plot of the evaluated and identified deep energy levels HT1-HT6 and ET1

Deep energy level parameters that were calculated by LSQ algorithm are listed in Table 2 and it is possible to compare them with the results of other evaluation methods. All deep energy levels were confirmed by LSQ algorithm evaluation and the existence of other deep energy levels in the grey areas of Fig. 4 is suggested. Small differences in the values of the deep energy level parameters obtained by different evaluation methods don't refer to the calculation error, but rather confirm the use of different physical models in the evaluation analysis.

\section{Conclusion}

DLTS study of p-i-n structure (NI71n) based on the triple quantum well (MQW) InGaAsN/GaAs heterostructure with the application of the numerical algorithm evaluation is presented in this paper. Several electrically active deep energy levels were confirmed. The parameters of the identified deep energy levels were calculated by three methods of evaluation with high level of precision. The assignment to the previously known defects of the evaluated deep energy levels was suggested. Emission of the charge carriers from the quantum well was observed and identified as an energy level HT1 $(0.038 \mathrm{eV})$. Seven more hole energy levels and one electron energy level were identified and related to known material and growth defects of GaAs. Out of them two energy levels (HT3 and HT6) were identified as contaminations.

\section{Acknowledgement}

This work has been supported by the Scientific Grant Agency of the Ministry of Education of the Slovak Republic (Projects VEGA 1/0377/13 and VEGA 1/0439/13). This work was co-financed by the Polish Ministry of Science and Higher Education under the grant No. N N515 607539, by the European Union within European Regional Development Fund, through grant Innovative Economy (POIG.01.01.02-00-008/08-05), by Wrocław University of Technology statutory grant and SlovakPolish International Cooperation Program No. SK-PL-0005-12.

\section{References}

[1] WISTEY, M. A.: Growth of 1.5 um GaInNAsSb Vertical Cavity Surface Emitting Lasers by Molecular Beam Epitaxy, Stanford University Thesis, 2005.

[2] MILANOVA, A. M. et al.: J. Optoelectronics and Advanced Materials, vol. 11, No. 10, pp. 1471-1474, 2009.

[3] STUCHLIKOVA, L. et al.: DLTFS Study of p-i-n Diode Based on InGaAsN/GaAs Multi-Quantum Well Structure, APCOM 2013. Applied Physics of Condensed Matter : Proceedings of the $19^{\text {th }}$ Intern. Conference, Strbske Pleso, 2013.

[4] PUCICKI,. D. et. al: XIV European Workshop on Metalorganic Vapor Phase Epitaxy, Wroclaw, Poland, 2011, p. 287.

[5] RYBAR, J., KOSA, A., STUCHLIKOVA, L.: Deep Level Parameters Calculation Using Fitting Evaluation Analysis in Digital DLTS MeasurementsS," Proc. of ADEPT, High Tatras, 2013, pp. 262-265.

[6] MitonneAU, A., MARTIN, G. M., MIRCEA, A.: Hole Traps in Bulk and Epitaxial GaAs Crystals, Electronics Letters, vol. 13, No. 22, pp. 666-668, 1977.

[7] DEENAPANRAY, P. N. K., PETRAVIC, M., JAGADISH, C., KRISPIN, M., AURET, F. D.: Electrical Characterization of p-GaAs Epilayers Disordered by Doped spin-on-Glass, J. of Applied Physics, vol. 97, No. 3, 2005. 


\section{COMMNICOIIONS}

[8] LAGOWSKI, J., LIN, D. C., CHEN, F., SKOWRONSKI, M., GATOS, H. C.: Native Hole Trap in Bulk GaAs and its Association with the Double-charge state of the arsenic antisite defect, Applied Physics Letters, vol. 47, No. 9, p. 929, 1985.

[9] KLEVERMAN, M., OMLING, P., LEDEBO, L. A., GRIMMEISS, H. G.: Electrical Properties of Fe in GaAs, J. of Applied Physics, vol. 54, No. 2, 1983.

[10] YU, P. W., REYNOLDS, D. C., STUTZ, C. E.: Sharp-line Photoluminescence of GaAs Grown by Low-temperature Molecular Beam Epitaxy, Applied Physics Letters, vol. 61, No. 12, p. 1432, 1992.

[11] BOURGOIN, J. C., NEFFATI, T.: The Energy Level of the EL2 Defect in GaAs, Solid-State Electronics, vol. 43, No. 1, p. 153-158, 1999. 